\title{
The Effect of Different Concentration of Aqueous Extracts of Labisia pumila in Preventing Osteoporosis and Improvement of Dermal Elasticity in Polycystic Ovary Syndrome Rats
}

\author{
Alif Aiman Zakaria \\ Universiti Putra Malaysia \\ Mohd Qayyum Ab Latip \\ Universiti Putra Malaysia \\ Tengku Rinalfi Putra Tengku Azizan \\ Universiti Putra Malaysia \\ Hafandi Ahmad \\ Universiti Putra Malaysia \\ Mazlina Mazlan \\ Universiti Putra Malaysia \\ Hasliza Abu Hassim \\ Universiti Putra Malaysia \\ Mohd Hezmee Mohd Noor ( $\nabla$ hezmee@upm.edu.my ) \\ Universiti Putra Malaysia https://orcid.org/0000-0003-0762-9242
}

\section{Research}

Keywords: Labisia pumila, PCOS, osteoporosis, skin elasticity

Posted Date: July 1st, 2021

DOI: https://doi.org/10.21203/rs.3.rs-643800/v1

License: (c) (i) This work is licensed under a Creative Commons Attribution 4.0 International License. Read Full License 


\section{Abstract}

Background: Labisia pumila (LP) a Malaysian herb thought to have phytoestrogenic effects in rats with PCOS. In this study we investigate the effects of LP aqueous extracts on bone composition, bone biomarkers and metabolic disorder in female rats fed continuously with high fat diet to induce PCOS.

Hypothesis: The administration of Labisia pumila treatment in PCOS rats for 90 days will ameliorate the adverse effect of osteoporosis by reducing the inflammatory cytokine and improving the dermal elasticity of PCOS rats.

Study design: On the 90th day of the development of PCOS model rats fed with high fat diet and after the vaginal smear analysis indicating a prolonged estrus cycle of more than 2 weeks, all PCOS rats were divided into 4 groups which consisted of control, placebo (water), LP25 (LP 25mg/kg) and LP50 (LP 50 $\mathrm{mg} / \mathrm{kg}$ ) respectively. All PCOS continue to received the formulated high fat diet and control animals continued to received normal chow and water ad libitum.

Method: Vehicle and treatments, which were given orally by using stomach gavaging needle size 16 gauge straight and curve retrolingual administration. The rats were sacrificed at the end of the trial phase and organs, tissues and blood samples were harvested for multiple assays and analysis listed below.

Results: The level of estradiol was significantly increased in LP25 and LP50 as compared with placebo. The inflammatory cytokine of C-reactive protein and TNF- $\$ were significantly decreased in LP25 and LP50.

Conclusion: Treatment of LP extract might reduce the inflammatory cytokine related to the formation of osteoporosis and loss of bone mass, increase the insulin sensitivity and reduce of osteoporosis in PCOS patients. The phytoestrogenic of LP all of the above significant positive results are proven in lowering osteoporosis and metabolic disorder in PCOS rats.

\section{Introduction}

The women reproductive disease such as polycystic ovary syndrome (PCOS) is a hormonal disorder that affects women in their reproductive age. Women with PCOS tend to have prolonged menstrual cycle and excess of male hormone such as androgen. The polycystic ovary syndrome describes the development of cysts that form in the ovaries. However, some women with PCOS disorder do not have cysts. There is a link that obesity can cause PCOS. The main cause of the disease development is still unclear. PCOS is common endocrinology disease that affecting women on their reproductive age at almost $10 \%$ (Goodarzi et al., 2011) and studies have shown that almost $40 \%-80 \%$ of the PCOS are affected by obesity (Sam, 2007). The most common symptoms of PCOS are insulin resistance, irregular estrus cycle and hyperandrogenism. Recent studies suggest that hyperandrogenic condition is cause by genetic inheritance governing the steroid hormone synthesis due to maternal inheritance (Ashraf et al., 2019). The major underlying cause of PCOS is due to obesity which is linked to overconsumption of high fat diet 
(Roberts et al., 2017). The stimulation of high fat diet to normal rats can results the same PCOS as human. Some rats model had been expose to nanoromatizable dihydrotestosterone (DHT), starting before puberty to results in polycystic ovary morphology, adiposity and enlarge in adipocytes and insulin resistance (Mannerås et al., 2007).

Report have suggested clinical diagnosis of PCOS can be classified as two of the three criteria of symptoms (i) hyperandrogenism (ii) chronic anovulation and (iii) polycystic ovaries (Group, 2004). Apart from that, women with PCOS tend to develop other chronic metabolic disorder such as weight gain, insulin resistance, hyperinsulinemia, hyperlipidemia and abdominal adiposity (Dunaif et al., 1989). The insulin elevation can be very alarming in PCOS model, and it plays an important role in pathophysiology of PCOS model on $50-70 \%$ of patient (Mannerås et al., 2010). Increase in insulin thus related to elevation of androgen production, which cause the metabolic disturbance in PCOS model. Furthermore, the increase in insulin in PCOS model have an influence on the bone metabolism which lead to osteoporosis condition (Katulski et al., 2014).

PCOS is the common disorder-affecting women mostly due to unhealthy diet and lifestyle. Some of the health conditions found are osteoporosis and poor dermal elasticity. The current modern treatment of PCOS includes drugs medication and surgery is very costly and high risk. Natural product such as Labisia pumila is abundant in nature and has been proven safe for human consumption.

This study is design to study the development of polycystic ovary syndrome induce by high fat diet and the preventive action of different concentration of Labisia pumila extract on osteoporosis in PCOS rats and improvement of dermal elasticity. The study examines on three major research questions, which is, could the high fat diet induce PCOS in rats. Secondly, could the Labisia pumila prevent the osteoporosis in PCOS rats. Thirdly, could the different concentration of Labisia pumila improve dermal elasticity in PCOS rats induce by HFD.

\section{Methodology}

\subsection{Animal Management}

Thirty-six female Sprague Dawley rats at the age of 12 weeks rats (B.W: $250 \pm 30 \mathrm{~g}$ ) supplied from Animal Resource Unit, Department of Veterinary Pathology and Microbiology, Faculty of Veterinary Medicine were used in this study. This protocol was approved by the Institutional Animal Care and Use Committee (IACUC) at UPM (UPM/IACUC/AUP-R038/2019).

\subsection{Development of High Fat Diet (HFD)}

All rats were divided into five groups PCOS model with HFD $(n=30)$ and control group with standard diet, $(n=6)$. The PCOS rats were fed with HFD for 90 days. Rats in control group were fed with standard diet. The HFD were composed of $40 \%$ fat, $30 \%$ carbohydrates and $30 \%$ glucose, with a total caloric value of 
$334 \mathrm{kcal} / \mathrm{kg}$ and standard chow diet composed of $3 \%$ fat and $21 \%$ protein with total caloric value of 25 $\mathrm{kcal} / \mathrm{kg}$ were purchased from Gold Coin, Selangor, Malaysia.

\subsection{Measurement and analysis of body weight, vaginal smear and serum biochemistry}

Body weight measured weekly from day 1 of feeding high fat diet to determine the average weekly weight gain of PCOS rats. Blood samples obtained from all rats fasting for $12 \mathrm{~h}$ were centrifuged at $2500 \mathrm{rpm}$ for 10 min and stored at $-80^{\circ} \mathrm{C}$. Serum levels of glucose, cholesterol, creatinine, ALT, AST, ALP will determined the stage of cyclicity from of the age 56 days to the end of experiment. In this procedure, vaginal smear obtained by vaginal washing were dyed with methylene blue and analyzed under microscope for the predominant cell type in vaginal smears. The estrus cycle experiences four stages of proestrus, estrus, metestrus and diestrus phase. Cycles with duration of 4-5 days were considered as regular. At the beginning of experiment, all rats showed regular estrus cycle.

\subsection{Experimental design}

On the 90th day of the development of PCOS model rats after the vaginal smear analysis indicating a prolonged estrus cycle of more than 2 weeks. All the PCOS rats were divided into 6 groups which consisted of normal, placebo (water), LP25 (LP $25 \mathrm{mg} / \mathrm{kg}$ ) and LP50 (LP $50 \mathrm{mg} / \mathrm{kg}$ ). All PCOS continue to received the formulated high fat diet and control animals continued to received normal chow and water ad libitum. Vehicle and treatments, which were given orally by using stomach gavage with needle size 16 gauge straight and curve retrolingual administration. The rats were sacrificed at the end of the trial phase and organs, tissues and blood samples were harvested for multiple assays and analysis listed below.

\subsection{Measurement of Serum C-reactive protein, TNF-alpha, Testosterone, Estradiol and Insulin by ELISA}

Results of PCOS rats' C-reactive protein, TNF-alpha, testosterone, estradiol and insulin in serum of control and treated PCOS rats were measured by ELISA for c-reactive protein (PTX 1), Testosterone, Estradiol and ALPCO's Insulin ELISA (Abcam, United Kingdom). The process of ELISA was incubating a specific monoclonal anti-rat HRP-conjugate in an anti-mouse IgG-coated microtiter wells for 60 minutes at 20$24^{\circ} \mathrm{C}$. The samples undergo washing of standard, and control. Adding a releasing agent and chromogenic substrate will eventually bound to HRP- conjugate form colour substrate. The reaction was stope using stop solution and measured the absorbance reading at $450 \mathrm{~nm}$ at microtiter plate reader.

\subsection{Bone Scanning Electron Microscope (BSEM)}

First, $\mathrm{H}_{2} \mathrm{O}$ was removed from the samples. After the samples were dry, the samples were affixed to specimen holder and then cleaned by hand blower. Once the samples were ready, they then were put into the specimen chamber to be observed and analyzed for their micro structure on the SEM screen. Results of the SEM image then would indicate their topography (their surface texture) and morphology (shape and size of particles arranging them). 


\subsection{Bone Calcium Content Analysis}

Bone calcium content measurement was performed using Leco's Inductive Couple Plasma atomic emission spectroscopy at Material Characterization Laboratory, Department of Chemical and Environmental Engineering, Faculty of Engineering, UPM. The bones were dried in an oven at $600{ }^{\circ} \mathrm{C}$ for $24 \mathrm{~h}$. The bones were then crush into ashes. The ash is weighed and dissolved in $3 \mathrm{ml}$ nitric acid and diluted in lanthanum chloride. The calcium chloride was measure at $422.7 \mathrm{~nm}$.

\subsection{Micro-CT Analysis}

X-ray micro-CT (Skyscan 1172, Bruker, Germany) were used to assessed LP supplement on trabecular bone. The bone of left humerus was placed in a sample holder in a vertical direction. The epiphyseal head facing downward to maximise the scanning process. The source energy selected for this study were $70 \mathrm{KVp}$ and $114 \mu \mathrm{A}$.

\subsection{Skin and Vaginal Elasticity Analysis}

Before the biomechanical analysis was performed, both skin (on the ventral part of the rats) and vaginal tissue were harvested from the euthanised animals. The skin and vaginal tissue was collected and stored with $0.9 \%$ normal saline. The samples was stored at $0-4^{\circ} \mathrm{C}$ in a refrigerator. The samples were allowed to equilibrium at reach room temperature. The samples were cut into a bone shape with an aspect ratio of 7 $\mathrm{cm}$ where the testing areas is $5 \mathrm{~cm}$ in length and $2 \mathrm{~cm}$ for clamp grip on the tissue using a specially design soft tissue clamp. This is to ensure a uniform distribution of stretch. The special design sampleclamp was attached to a uniaxial tensile testing machine (Instron ${ }^{\mathrm{TM}}$ Universal Testing Machine 5566). The setting of the machine was set at preloaded to 1 Newton.

During the testing, samples were hyrdated with $0.9 \%$ saline solution. The cyclic preconditioning was not performed prior to the load to failure test. The universal testing machine were stretch at rate of 15 $\mathrm{mm} / \mathrm{min}$. Data produce from the testing were presented as load (Newtons) and elongation (millimeters). The stretched produce result of load-elongation curve was generated for each test. This experiment represents the mechanical strength of the tissue. Data of tangent modulus (MPa) $d$ from this curve was analyzed in the linear region. The tangent modulus result form long-elongation of the stretch is an indicator of tissue stiffness on a per unit basis.

\section{Statistical Analysis}

Data obtained were expressed as mean \pm SEM. The Wilck-Shapiro test used for statistical analysis for normal distribution. Single factor analysis of variance (ANOVA) were used for multiple comparison between the data. The analysis followed by post hoc comparisons with the Tukey test, according to the GraphPad Prism V 5.1. Differences were considered significant at $p<0.05$.

\section{Results}




\subsection{Body weight of PCOS rats}

There were no significant change in the body weight rats given with high fat diet throughout experimental period (Fig. 1). However, there is significant increase in Placebo group compare to control and treatment group LP 25 and LP 50.

\subsection{Measurement of Serum levels of glucose, cholesterol, creatinine, ALT, AST, ALP}

The results show serum biochemistry of PCOS throughout the experimental period given with high fat diet (Table 1). All the experimental group showed an increase level of glucose throughout 90 days of experimental period.

Table 1

Serum biochemistry levels of glucose, cholesterol, creatine, ALT AST and ALP

\begin{tabular}{|c|c|c|c|c|c|}
\hline Parameter /Group & CONTROL & PLACEBO & $\begin{array}{l}\text { LP } 25 \\
(25 \\
\mathrm{mg} / \mathrm{kg})\end{array}$ & $\begin{array}{l}\text { LP } 50 \\
(50 \\
\mathrm{mg} / \mathrm{kg})\end{array}$ & $\begin{array}{l}\text { NORMAL RANGE } \\
\text { VALUE }\end{array}$ \\
\hline Urea (mmol/L) & 6.15 & 2.95 & 3.40 & 4.45 & $0.73-1.50$ \\
\hline Creatinine $(\mu \mathrm{mol} / \mathrm{L})$ & 58.0 & 71.5 & 62.0 & 62.0 & $17.68-53.05$ \\
\hline $\begin{array}{l}\text { ALT } \\
(\mathrm{U} / \mathrm{L})\end{array}$ & 52.0 & 128.5 & 52.5 & 58.5 & $16-48$ \\
\hline $\begin{array}{l}\text { AST } \\
(\mathrm{U} / \mathrm{L})\end{array}$ & 196.0 & 378.0 & 125.5 & 154.0 & $65-203$ \\
\hline $\begin{array}{l}\text { ALP } \\
(\mathrm{U} / \mathrm{L})\end{array}$ & 87.0 & 115.0 & 90.5 & 95.50 & 26.147 \\
\hline Glucose (mmol/L) & 12.20 & 16.05 & 11.10 & 10.90 & $1.33-4.05$ \\
\hline $\begin{array}{l}\text { Cholestrol } \\
\text { (mmol/L) }\end{array}$ & 2.10 & 2.35 & 2.00 & 1.95 & $4.22-9.71$ \\
\hline
\end{tabular}

\subsection{Estrus cycle of PCOS rats}

The results show the estrus cycle of PCOS rats given with high fat diet. The experimental group placebo, LP 25 and LP 50 shows a prolonged estrus cycle compared to the control group throughout 90 day of experimental period (Figs. 2, 3, 4 and 5)

\section{Anti-Osteoporotic experiment:}




\subsection{Bone calcium content analysis PCOS rats}

The bone calcium content of PCOS rats show no statistical significant between all treatment groups. However, LP 50 shows the highest level of bone calcium content in PCOS (Fig. 6).

\subsection{Micro-CT analysis of PCOS rats}

The total porosity of PCOS showed no significant results as compared with PLACEBO (Fig. 7). However, all treatment group showed lower levels of concentration of total porosity compared with PLACEBO. LP 50 showed the lowest level of total porosity in PCOS rats. PLACEBO showed the highest level of total porosity in PCOS rats.

\subsection{Bone Scanning Electron Microscope (BSEM) of PCOS rats}

The bone scanning electron microscope show the image of porosity surface area (Figs. 8, 9, 10 and 11). The placebo group show the highest level of percentage porosity $33.67 \%$ compared to control $19.54 \%$ (Table 2). LP 50 show the lowest percentage porosity of $14.52 \%$, while LP 25 show $17.02 \%$ compared to control group in (Table 2).

Table 2

Percentage of Porosity surface area of PCOS rats

\begin{tabular}{|ll|}
\hline GROUP & PERCENTAGE OF POROSITY SURFACE AREA \\
\hline Placebo & $33.67 \%$ \\
\hline Control & $19.54 \%$ \\
\hline LP 25 & $17,02 \%$ \\
\hline LP 50 & $14.52 \%$ \\
\hline
\end{tabular}

\subsection{Serum C-reactive protein assay of PCOS rats}

C-reactive protein assay of PCOS rats and * bars indicate statistical significance at $p<0.05$ (Fig. 12). Creactive protein of PCOS showed a significant decrease given with LP 25 and LP 50 alone as compared with placebo. Control group showed a significant decrease as compared with placebo.

\subsection{Serum TNF-alpha assay of PCOS rats}

TNF-Alpha assay of PCOS rats and * bars indicate statistical significance at $\mathrm{p}<0.05$ (Fig. 13). TNF- alpha showed a significant decrease given with treatment LP 25 and LP 50 when compared with placebo. Control also showed a significant decrease when compared with placebo.

\subsection{Estradiol assay of PCOS rats}


Estradiol assay of PCOS rats and * bars indicate statistical significance at $p<0.05$ (Fig. 14). The treatment LP 25 and LP 50 showed a significant increase in Estradiol level as compared with placebo. Control also showed a significant increase as compared with placebo

\subsection{Testosterone assay of PCOS rats}

Testosterone assay of PCOS rats and * bars indicate statistical significance at $p<0.05$ (Fig. 15). Control, LP 25 and LP 50 showed a significant decrease in testosterone when compared with placebo. Control, LP 25 and LP 50 showed the same level of significant decrease in testosterone as compared with placebo.

\subsection{Insulin assay of PCOS rats}

Insulin assay of PCOS rats and * bars indicate statistical significance at p < 0.05 (Fig. 16). The Insulin showed a significant decrease in treatment LP 25 and LP 50 compared with placebo. control also showed a significant decrease in Insulin compared with placebo.

\subsection{Skin elasticity of PCOS rats}

The elasticity of skin and vagina was not significantly altered in all treatment group (Figs. 17 and 18). However, LP 50 significantly increase the level of skin elasticity. Treatment LP 25 and LP 50 showed the highest level both in skin and vaginal elasticity compared with PLACEBO.

\section{Discussion}

Obesity has become a major problem which lead to many chronic diseases such as insulin resistance, type 2 diabetes, cardiovascular disease and polycystic ovary syndrome (Guilherme et al., 2008). The over consumption of high calory diet which lead to reduction in energy utilization and subsequently results in insulin resistance promote the formation of obesity (X.A. et al., 2013). The high fat diet not only shows sign of metabolic impairment it also disturbs the female reproductive performance which can lead to polycystic ovary syndrome (PCOS). Polycystic ovary syndrome is the most common endocrinopathy and most frequent cause of infertility in women reproductive age. It is characterize by hirsutism, acne, anovulation, menstrual irregularities, hypeandrogenemia, hyperinsulinimea and polycystic ovary (Franks, 1995; Goodarzi et al., 2011). According to clinical diagnosis, PCOS requires the presentation of two of the three symptoms of hyperandrogenism, chronic anovulation and polycystic ovaries (Group, 2004). However, PCOS involve many metabolic impairments, the important role in pathophysiology of PCOS is $50-70 \%$ of patients have insulin resistance (Dunaif et al., 1989). In much severe cases, PCOS will in time develop to musculoskeletal disorders such as osteoporosis (Katulski et al., 2014), osteoarthritis (SanchezSantos et al., 2018) and tendinitis (Jewson et al., 2018). Due to the metabolic impairment in PCOS, it can lead to impairment skin cutaneous leading to loss of elasticity. The inflammatory plays a major role in the development of PCOS and other metabolic problem. 
Aqueous extracts of Labisa pumila (LP) is a herbal formula used in this study to determine the efficacy of its natural compound in correcting the effects of osteoporosis, hormonal imbalances and cutaneous disorders. In this study, we presented results showing that orally administrated different concentration of LP25 and LP50 (as stated in Methodology) decreases the osteoporosis, hormonal imbalances, inflammatory mediators level and increases the skin elasticity without any distinct toxicities in PCOS rats induced by HFD.

This study used two doses of LP alone $(25 \mathrm{mg} / \mathrm{kg}$ and $50 \mathrm{mg} / \mathrm{kg})$ were given at 5 times a week for a duration of 90 days duration of treatments to evaluate the dose effects on modulation of c-reactive protein, TNF-alpha, insulin, serum estradiol and testosterone levels pertaining to the osteoporosis effects by ELISA assay. It is important to note LP extract has been shown to be safe with an $\mathrm{LD}_{50}$ of more than $5.0 \mathrm{~g} / \mathrm{kg}$ (M.F. et al., 2007). According to other studies on LP extract was reported to exhibit no-adverseeffect-level (NOAEL) at the dose of $50 \mathrm{mg} / \mathrm{kg}$ in sub-acute (G.D. et al., 2009). At dose $1000 \mathrm{mg} / \mathrm{kg}$ in subchronic (S.C, 2004) and $800 \mathrm{mg} / \mathrm{kg}$ was reported to show no adverse effect level (NOEL) in reproductive toxicity studies (M.F. et al., 2007). However, in human, the effective doses normally taken by women are around $500-1000 \mathrm{mg} / \mathrm{kg}$ daily. Which is similar to $25 \mathrm{mg} / \mathrm{kg}$ and $50 \mathrm{mg} / \mathrm{kg}$ when calculate for animal trial. Therefore, the doses used in this study are considered to be safe. From the study, it showed that significant effects of anti-osteoporosis was detected in this experiment of PCOS rats treated with LP alone.

Labisia pumila contained phytoestrogenic properties that can upregulate the synthesis of estrogen in human. The antioxidant effects initiated by the estrogen can decrease lipid peroxidation of that will result in oxidative damage and indirectly help in free radical scavenging (S.P. et al., 2002). Furthermore, estrogen deficiency result in the decline bone formation and in turn increase bone resorption process leading to osteoporosis. It can be said that osteoporosis is the systemic skeletal disease characterized by low bone mass and micro-architecture deterioration of bone tissues which results in increase bone fragility and fracture (Norhayati et al., 2014). It is important to understand estrogen is a hormone that has a profound effect on bone physiology. It keep the bone turnover rate at balance and reduces the cause of osteoporosis which can be seen postmenopausal women.

Therefore, the doses used in this study are considered to be safe. From the study, it showed that significant effects of anti-osteoporosis were detected in-group of PCOS rats treated with LP25 and LP50. This indicates that extracts of LP alone managed to reduce the level of C-reactive protein, a cytokine that is used as an indicator for bone mass density. Increase levels of c-reactive protein in blood indicates a detrimental effects of this inflammatory cytokines towards bone health and mass, thus contributing towards the risk of fractures (Huang and Schooling, 2017).

In this study, it was found that the treatment of PCOS rats with LP25 and LP50 alone significantly reduced the levels of TNF- $a$ while the level in normal untreated and placebo groups of rats showed an increase in TNF- $a$ level at a significant rate. It was noted that increase in the level of TNF- $a$ correlates with other parameters that were investigated in this study and this point towards the outcome following PCOS 
induction in rats in term of bone calcium contents and micro-computed topography (micro-CT) results.

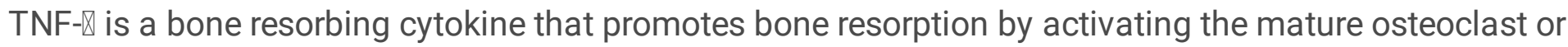
by stimulating the proliferation and differentiation of osteoclast (Lerner and Ohlin, 1993). The finding were consistent with fathilah et al 2012 and Choi et al 2010 that LP extract inhibit the TNF-a production in the experimental study (Choi et al., 2010; Fathilah et al., 2013). TNF-a promotes osteoclastogenesis by activating NF-KB transcription factor, which is also induced by RANK/RANK-L (Choi et al., 2010; Gilbert et al., 2005). Activation of NF-KB is a key target for TNF-a action through TNF receptor- 1 (TNFR-1), which is expressed on macrophages (Lam et al., 2000). This promotes pro-osteoclasts maturation even in the absence of RANK/RANK-L signaling (Bailey and Etherington, 1980). Tumor necrosis factors-alpha also enhances osteoclast differentiation by increasing the expression of M-CSF and RANK-L in osteoblasts (Affinito et al., 1999).

In this study, it was noted that the levels of estradiol was depleting in the placebo group while the treated group showed a normal levels of estradiol. At the same time, the levels of testosterone was at the normal level and elevated in the place group while the testosterone levels in treated group was at the normal range. The study shows that the LP extract proven to successfully replace the loss of estrogen due reduction in placebo group. In women with PCOS, secretion rate and metabolism of androgens and estrogens are impaired and androgens levels increase (Abasian et al., 2018). Estrogen plays a key role in the development and maintenance of appropriate bone mass. Estrogen regulates the adipocyte differentiation as well as skeletal growth and bone homeostasis. Estrogen acted on osteoblast and osteoclast for bone formation. However, in PCOS the estrogen and androgen were greatly altered which probably has great importance for bone metabolism in women. Estrogen deficiency also can be linked to the increase in food intake and body weight gain which result in obesity. Thus estrogen deficiency increase in adipose tissue proliferation on visceral fats which results in many chronic disease such as cardiovascular disease, osteoporosis and obesity. The LP extract able replace the hormone leptine resistin and adiponectin which in deficient placebo group. Which show the treatment group LP 25 and LP 50 able to maintain normal body weight gain.

The LP extract able to increase the insulin sensitivity of treated group LP 25 and LP 50 . The treatment of LP 25 and LP 50 does not affect the body weight gain of PCOS rats. It is reported that PCOS are more insulin resistant and body weight gain (Dunaif et al., 1989). This may be due to the phytoestrogenic effect of LP extract. According Manneras et al 2010 the supplementation of LP extract increases the insulin sensitivity up to $36 \%$ as well as improving the lipid profile of PCOS rats without affecting the body weight composition (Mannerås et al., 2010). LP extract possess uterotropic effects which regulate the body weight and lipid proliferation. Previously reported that reduction in plasma resistin increases the insulin sensitivity (26). This is linked to the high level adiponectin in PCOS rat treated with LP extracts (Weyer et al., 2001). Adiponectin is closely related to the metabolic abnormalities such as insulin sensitivity and obesity.

Results from bone scanning electron microscopy, micro-computed topography (micro-CT) and bone calcium contents showed that the administration of LP to the rats with PCOS have successfully replaced 
the estrogen from defective ovary in these PCOS rats at dosage LP $25 \mathrm{mg} / \mathrm{kg}$ and LP $50 \mathrm{mg} / \mathrm{kg}$. Phystoestrogen properties in LP can have an intricate pathways of action in improving the metabolic disorders such as PCOS and osteoporosis. It is reported that PCOS is a linked to ovulatory dysfunction, hyperandrogenism, abdominal fat, insulin resistance and polycystic ovaries (Group, 2004). In a much severe cases. PCOS can develop the loss of bone mass and density which can lead to osteoporosis. Osteoporosis is defined as systemic skeletal disease accompanied by low bone mass and microarchitecture deterioration of bone tissue. This consequently increase the chances to bone fragility and fractures (Grant et al., 1996). However, World Health Organization (WHO) reported osteoporosis can happened when the bone mineral density falls more than 2.5 Standard Deviations (SD) which is below the standard reference of young femaler maximum bone mineral density (Kanis et al., 2008). Form this experiment, LP 25 and LP 50 manage to significantly reduce the osteoporosis inflammatory cytokine

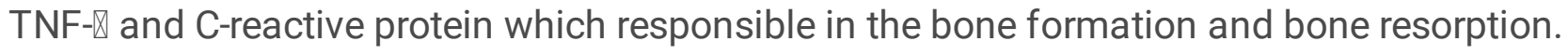

Supplementation of LP extract provide a beneficial aspect to estrogen deficiency women. It is reported at the age of 35-40, the bone mass in females begin to decline slowly, followed by a dramatic bone loss after menopause due to estrogen deficiency or surgical ovariectomy.

The result from skin and vaginal elasticity through biochemical testing did not altered the increase in elasticity of both tissues. However, the elasticity is still in normal range suggesting that LP extract did not change or possess any form of elasticity. The elasticity can be speculated whether to increase the concentration of LP extract given to PCOS rats. Other study suggested that the supplementation of LP extract can upregulate the synthesis of collagen human fibroblast cells (Choi et al., 2010). The LP extract can be used to protect the human skin from reactive oxygen species expose from UVB rays. Due to antioxidant and phenolic compound such as quercetin. This compound possesses rejuvenating effects on the skin repairing.

\section{Conclusion}

In conclusion the treatment of LP 25 and LP 50 significantly reduced the expression inflammatory cytokine related to the formation of osteoporosis in PCOS rat. The LP extract acted as an effective phytoestrogen for estrogen deficiency in PCOS rats. Increase the insulin sensitivity of without affecting the body weight of PCOS rats and reduced the risk of osteoporosis through oxidative properties of LP extract.

\section{Abbreviations}

LP, Labisia pumila; PCOS, polycystic ovary syndrome; TNF-a, tumor necrosis alpha; DHT, dihydrotestosterone; HFD, high fat diet; UPM, Universiti Putra Malaysia; BSEM, bone scanning electron microscope; SEM, scanning electron microscope; ALT, alanine transaminase; AST, aspartate transaminase; ALP, alkanline phosphate.

\section{Declarations}




\section{Funding:}

This research did not receive any specific grant from funding agencies in the public, commercial, or notfor-profit sectors.

\section{Ethics Approval and consent to participate:}

All experiments and care involving laboratory animal utilization were performed in accordance to the Universiti Putra Malaysia (UPM) Institutional Animal Care and Use Committee (IACUC) guidelines and approval with the certificate registration UPM/IACUC/AUP-R038/2019. The committee has reviewed and approved the proposed animal utilization protocol, subject to relevant permit and owner's consent.

\section{Consent of Publication:}

Not applicable

\section{Availability of Data and Materials:}

Please contact authors for data requests.

\section{Competing Interest:}

We wish to confirm that there are no known conflicts of interest associated with this publication and there has been no significant financial support for this work that could have influenced its outcome. The authors declare that they have no competing interest.

\section{Author contributions:}

A.A.: Carried out the animals studies and management, hormonal assays studies, inflammatory cytokine studies, dermal elasticity studies, statistical studies and drafted the manuscript; M. Q. A. : Participate in animals studies and management, hormonal assays studies, statistical studies and inflammatory cytokine assays studies T.R.P.T. : Contribute in coordination of studies; H. : Contribute in coordination of studies and management; $\mathbf{M}$. : Contribute in coordination of studies and management; H.A. : Contribute in coordination of studies and management; M.N.M. : Conceptualization the study design, coordination, management, investigation, supervision and helped to drafted the manuscript.

\section{Acknowledgment:}

The authors greatly thank Dr. Mohd Hezmee Mohd Noor, Dr. Hasliza Abu Hassim, Dr. Hafandi Ahmad, Dr. Mazlina Mazlan, Dr. Tengku Rinalfi Tengku Azizan and Mohd Qayyum Abdul Latip from Faculty of Veterinary Medicine, UPM, Malaysia and Department of Materialization, Faculty of Engineering, UPM, for providing the facility for this research and ideas for this studies.

\section{References}


1. Abasian Z, Rostamzadeh A, Mohammadi M, Hosseini M, Rafieian-kopaei M. A Review on Role of Medicinal Plants in Polycystic Ovarian Syndrome: pathophysiology, neuroendocrine signaling, therapeutic status and future prospects,v. Middle East Fertil Soc J. 2018;23:255-62.

2. Affinito P, Palomba S, Sorrentino C. Effects of postmenopausal hypoestrogenism on skin collagen. Maturitas. 1999;33:239-47.

3. Ashraf S, Nabi M, Rasool SulA, Rashid F, Amin S. 2019. Hyperandrogenism in polycystic ovarian syndrome and role of CYP gene variants: a review. Egypt J Med Hum Genet 20. https://doi.org/10.1186/s43042-019-0031-4.

4. Bailey AJ, Etherington DJ. Metabolism of collagen and elastin. In: Florkin M, Neuberger A, Van Dienen LLM, editors. Comprehensive Biochemistry. New York: Elsevier Scientific; 1980. pp. 408-31.

5. Choi H, Kim D, Kim JW, Ngadiran S, Sarmidi MR. Labisia pumila extract protects skin cells from photoaging caused by UVB irradiation. J Biosci Bioeng. 2010;109:291-6.

6. Dunaif A, Segal KR, Futterweit W, Dobrjansky A. Profound peripheral insulin resistance, independent of obesity, in polycystic ovary syndrome. Diabetes. 1989;38:1165-74.

7. Fathilah SN, Mohamed N, Muhammad N, Mohamed IN, Soelaiman IN, Shuid AN. Labisia pumila regulates bone-related genes expressions in postmenopausal osteoporosis model. BMC Complement Altern Med. 2013;13:217. https://doi.org/10.1186/1472-6882-13-217.

8. Franks S. 1995. Polycystic ovary syndrome. N Engl J Med 28;333(13).

9. G.D., S., M., G., M.S., Y., A., K., R., S., S., S., P.L., S., S., K., D.B., A., R.K, J., 2009. Sub-acute toxicity evaluation of an aqueous extract of Labisia pumila, a Malaysian herb. Food Chem. Toxicol 47, 2661-2665. https://doi.org/doi.

10. Gilbert L, Rubin J, Nanes M. The p55 TNF receptor mediates TNF inhibition of osteoblast differentiation independently of apoptosis. Am J Physiol Endocrinol Metab. 2005;288:1011-8.

11. Goodarzi MO, Dumesic DA, Chazenbalk G, Azziz R. Polycystic ovary syndrome: etiology, pathogenesis and diagnosis. Nat Rev Endocrinol. 2011;2:219-31.

12. Grant SF, Reid DM, Blake G, Herd R, Fogelman I, Ralston SH. Reduced bone density and osteoporosis associated with a polymorphic Sp1 binding site in the collagen type I a 1 gene. Nat Gen. 1996;14:203-5.

13. Group TREP, consensus workshop. 2004. Revised 2003 consensus on diagnostic criteria and longterm health risks related to polycystic ovary syndrome (PCOS) 19, 41-47. https://doi.org/10.1093/humrep/deh098.

14. Guilherme A, Virbasius JV, Puri V, Czech MP. n.d. Adipocyte dysfunctions linking obesity to insulin resistance and type 2 diabetes. Nat Rev Mol Cell Biol 9, 367-77.

15. Huang JV, Schooling CM. Inflammation and bone mineral density: A Mendelian randomization study. Sci Rep. 2017;7:8666.

16. Jewson J, Teede H, Lambert G, Jona E, Shorakae S, Gaida J. 2018. Musculoskeletal and Achilles Tendon Symptoms in Women with PCOS. J. Sci. Med. Sport. 
17. Kanis JA, Burlet N, Cooper C, Delmas PD, Reginster JY, Borgstrom F, Rizzoli R. European guidance for the diagnosis and management of osteoporosis in postmenopausal women. Osteoporos Int. 2008;19:399-428.

18. Katulski K, Slawek S, Czyzyk A, Podfigurna-Stopa A, Paczkowska K, Ignaszak N, Podkowa N, Meczekalski B. 2014. Bone mineral density in women with polycystic ovary syndrome. J Endocrinol Invest 24.

19. Lam J, Takeshita S, Barker J, Kanagawa O, Ross P, Teitelbaum S. TNF-alpha induces osteoclastogenesis by direct stimulation of macrophages exposed to permissive levels of RANK ligand. J Clin Invest. 2000;106:1481-8.

20. Lerner UH, Ohlin A. Tumor necrosis factors $\alpha$ and $\beta$ can stimulate bone resorption in cultured mouse calvariae by a prostaglandin-independent mechanism. J Bone Miner Res. 1993;8:147-55.

21. M.F., W.E., S., S.A., A.W.M., S., S.S.J, M., 2007. Evaluation of the female reproductive toxicity of aqueous extract of Labisia pumila var. alata in rats. Indian J. Pharmacol 39, 30-32.

22. Mannerås L, Cajander S, Holma A, Seleskovic Z, Lystig T, Lo M, Stener-victorin E. 2007. A New Rat Model Exhibiting Both Ovarian and Metabolic Characteristics of Polycystic Ovary Syndrome 148, 3781-3791. https://doi.org/10.1210/en.2007-0168.

23. Mannerås L, Fazliana M, Nazaimoon WMW, Lönn M, Gu HF, Östenson CG, Stener-victorin E. 2010. Beneficial metabolic effects of the Malaysian herb Labisia pumila var. alata in a rat model of polycystic ovary syndrome 127, 346-351. https://doi.org/10.1016/j.jep.2009.10.032.

24. Norhayati MN, George A, Nik Hazlina NH, Azidah AK, Idiana HI, Law KS, Bahari IS, Wan Zahiruddin WM, Liske E, Azreena A. Efficacy and safety of Labisia pumila var alata water extract among pre- and postmenopausal women. J Med Food. 2014;17:929-38. https://doi.org/10.1089/jmf.2013.2953.

25. Roberts JS, Perets RA, Sarfert KS, Bowman JJ, Ozark PA, Whitworth GB, Blythe SN, Toporikova N. n.d. High-fat high-sugar diet induces polycystic ovary syndrome in a rodent model. Biol. Reprod. 96, 551562. https://doi.org/10.1095/biolreprod.116.142786.

26. S.C, T., 2004. Sub-Chronic (90 days) Oral Toxicity Studies of Aqueous Extract of Labisia pumila in Wistar Rats (250,500 \& 1000 mg/kg b. wt. only) Indian Institute of Integrative Medicine.

27. S.P., C., W.S., Y., S.K., L., W.K., M., J.S., P., S.B, K., 2002. Effects of hormonal replacement therapy on oxidative stress and total antioxidant capacity in postmenopausal hemodialysis patients. Ren Fail $24,49-57$.

28. Sam S. n.d. Obesity and polycystic ovary syndrome. Obes Manag 3, 73.

29. Sanchez-Santos M, Rubin K, Glintborg D, Andersen M, Kluzek S, Abrahamsen B. Prevalence and clinically diagnosed incidence of knee, joint and hand osteoarthritis in woman with polycystic ovary syndrome:. a National Register-Based Study.Osteoarthritis and Cartilafe; 2018.

30. Weyer C, Funahashi T, Tanaka S, Hotta K, Matsuzawa Y, Pratley RE. n.d. Hypoadiponectinemia in obesity and type 2 diabetes: close association with insulin resistance and hyperinsulinemia. J Clin Endocrinol Metab 86, 1930-5. 
31. X.A., W., S., D., D., J., R., Z., S., Z., J., Z., L., Y., T., W., S., H., S., G., 2013. CARD3 deficiency exacerbates diet-induced obesity, hepatosteatosis, and insulin resistance in male mice. Endocrinology 154, 685697.

\section{Figures}

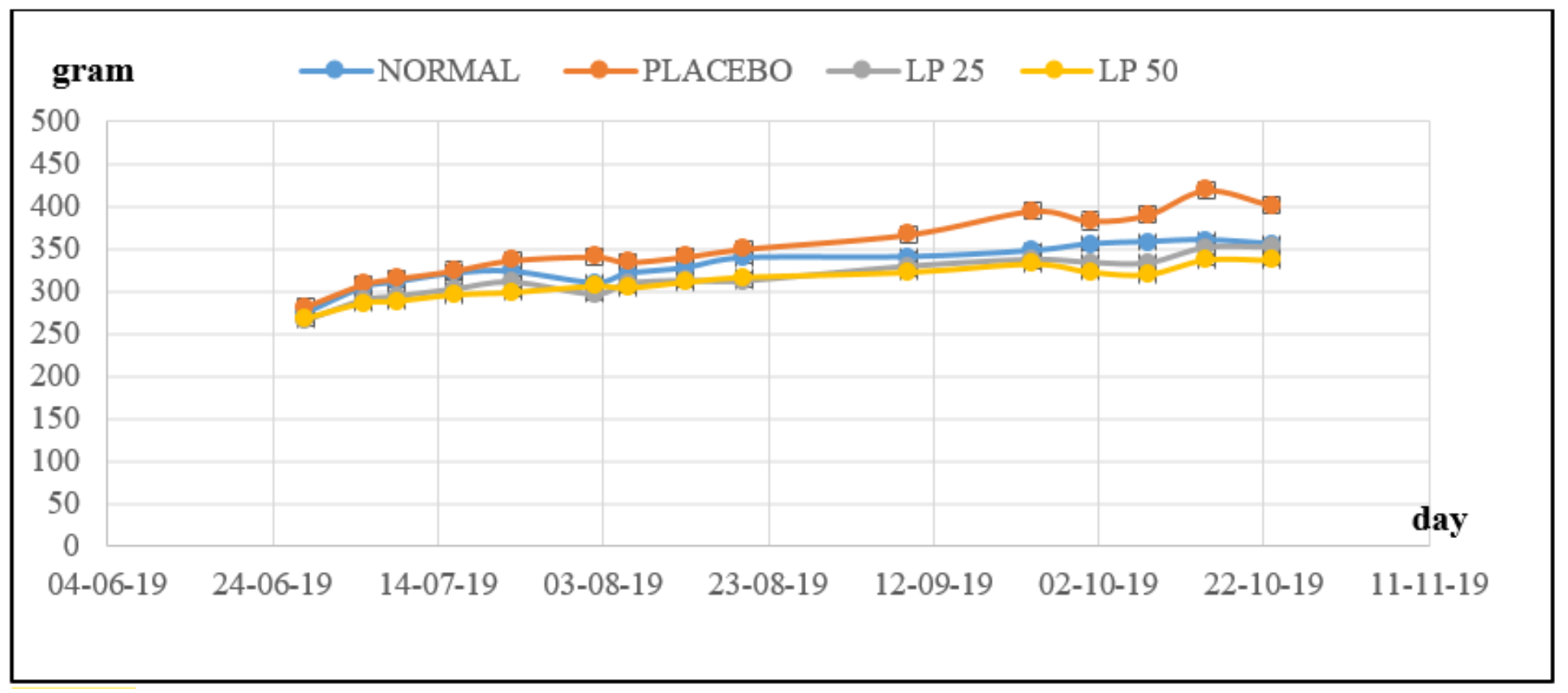

\section{Figure 1}

Body weight of PCOS rat. No significant changes in statistical analysis.

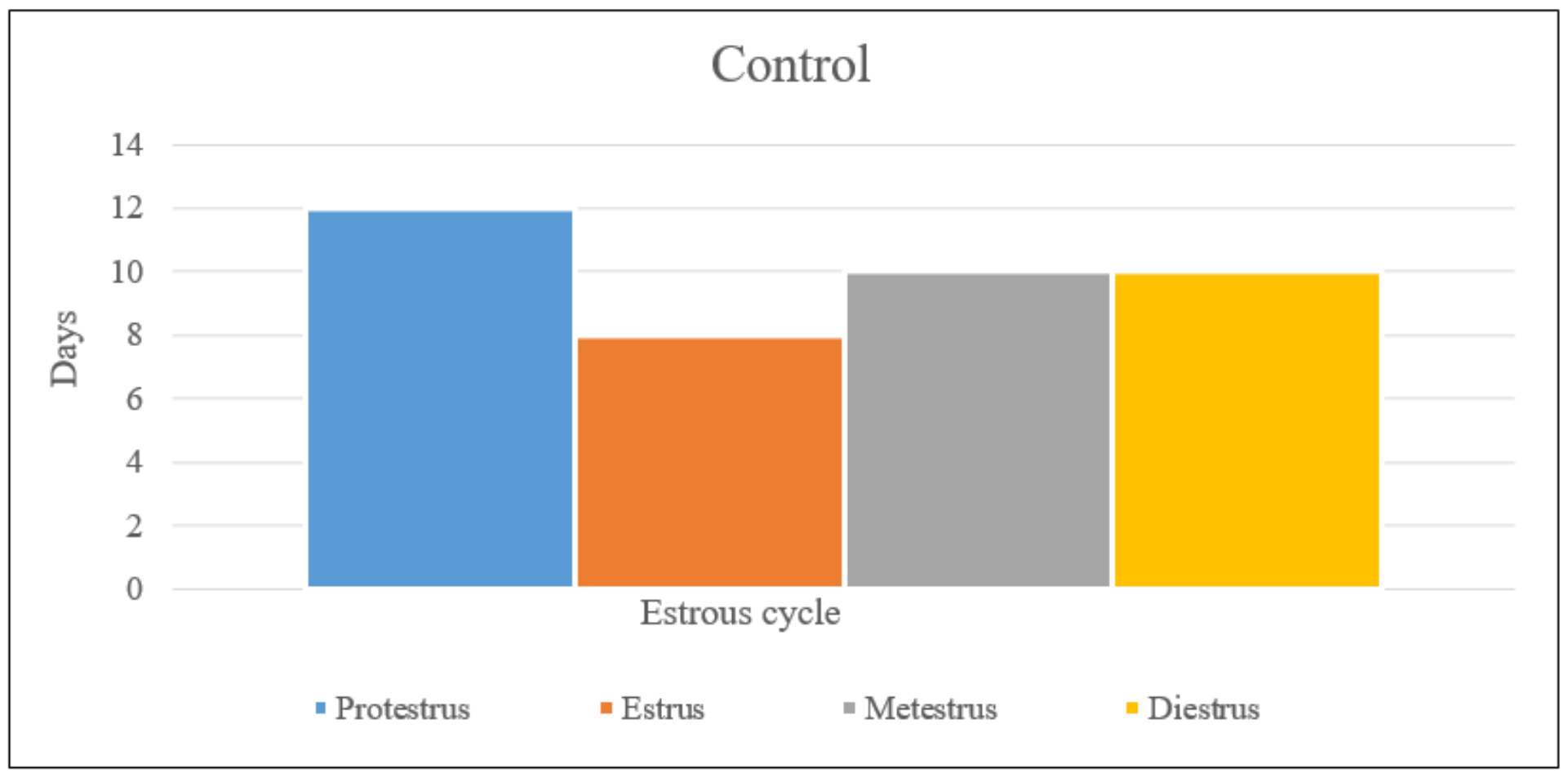


Figure 2

Estrous cycle of control rats. No significant changes in statistical analysis.

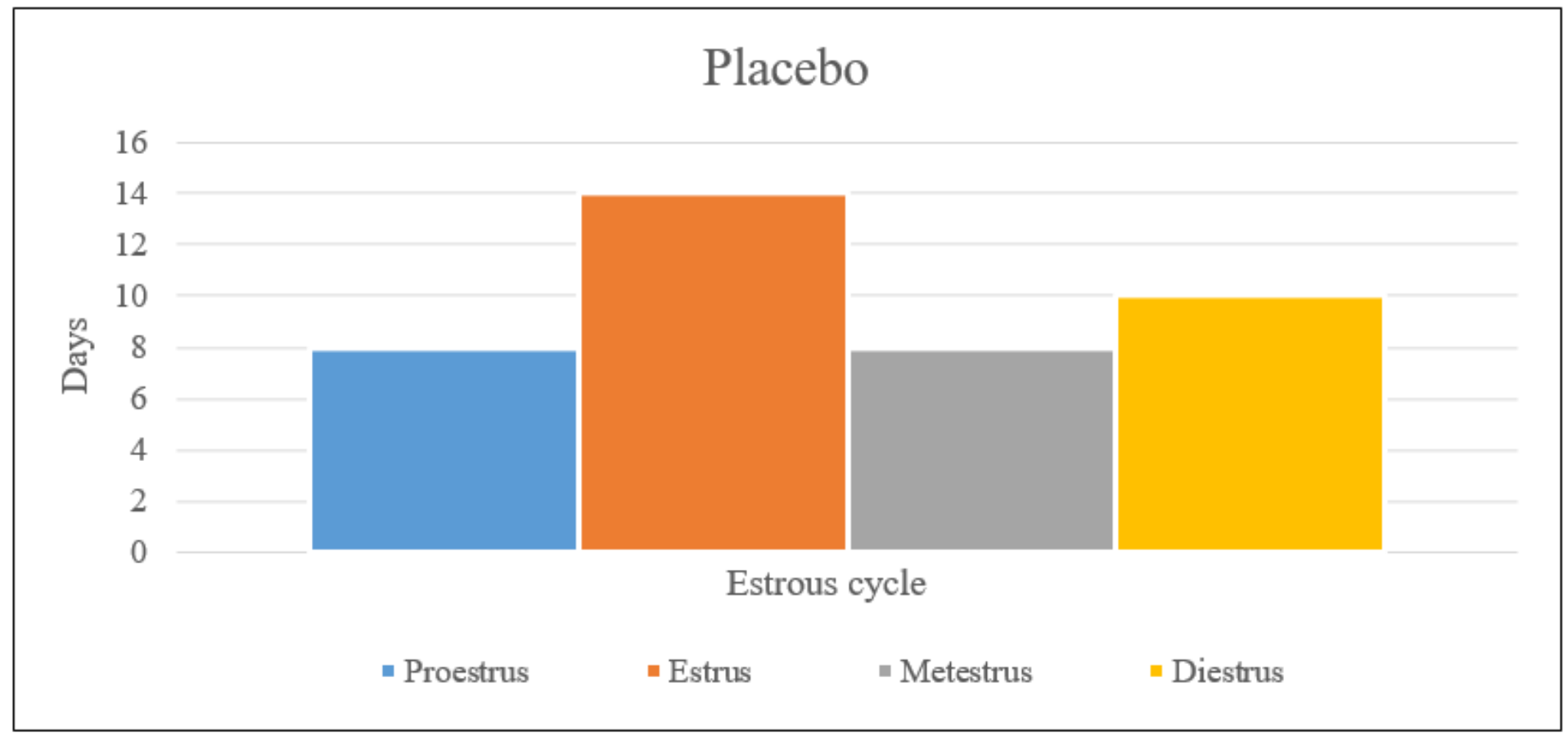

\section{Figure 3}

Estrous cycle of Placebo rats. No significant changes in statistical analysis.

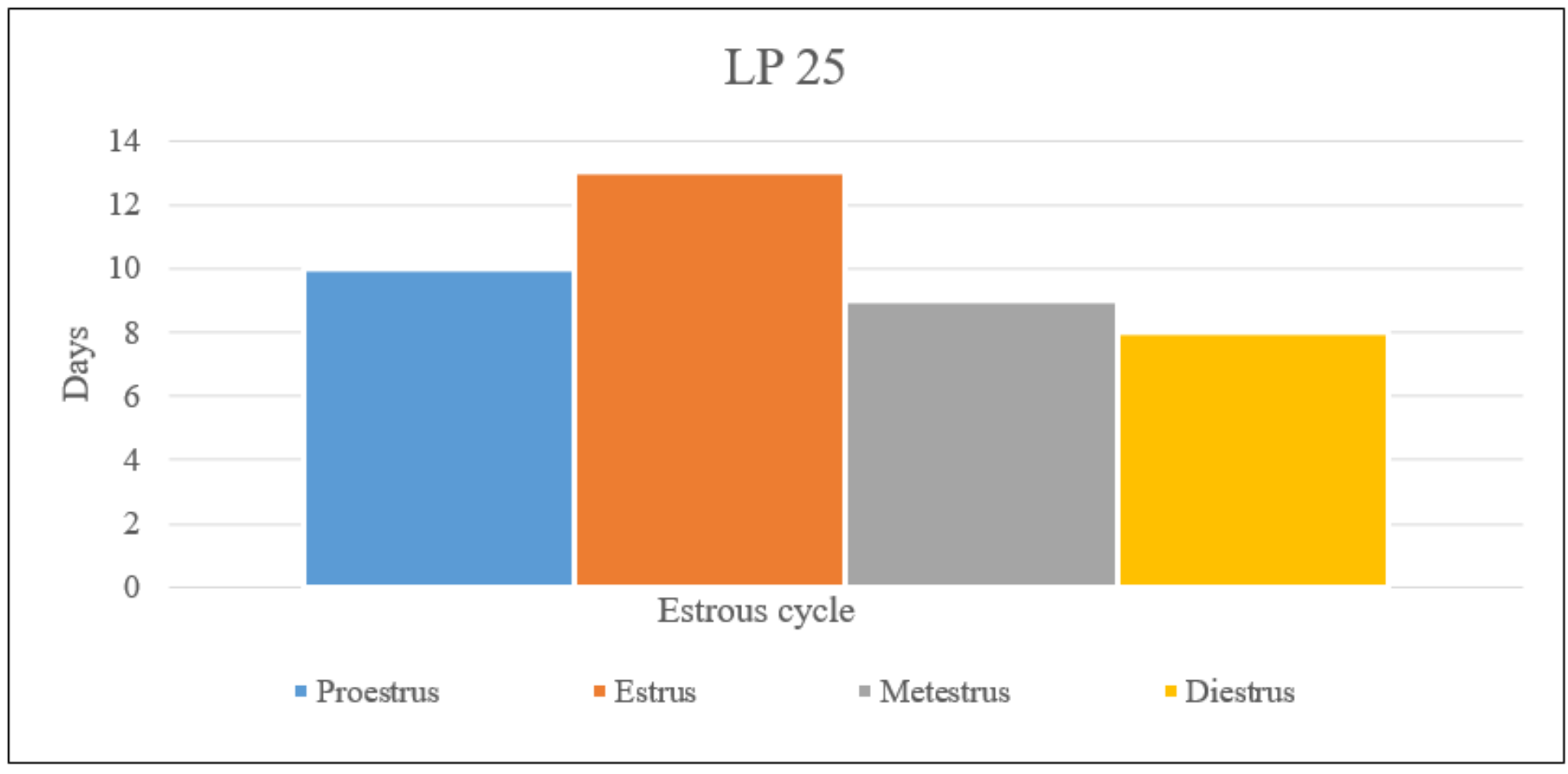

\section{Figure 4}

Estrous cycle of LP 25 PCOS rats. No significant changes in statistical analysis. 


\section{LP 50}

14

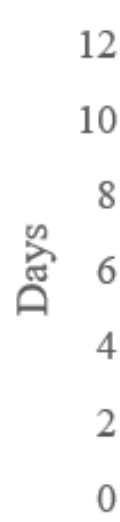

12

10

6

4

2

0
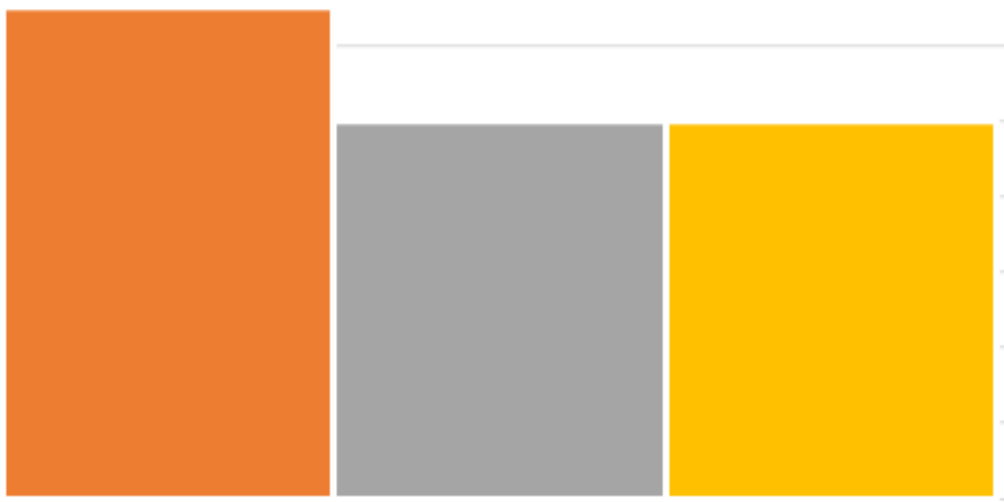

Estrous cycle

- Proestrus $\quad$ Estrus $\quad$ Metestrus $\quad$ Diestrus

Figure 5

Estrous cycle of LP 50 PCOS rats. No significant changes in statistical analysis.

Bone Calcium Content

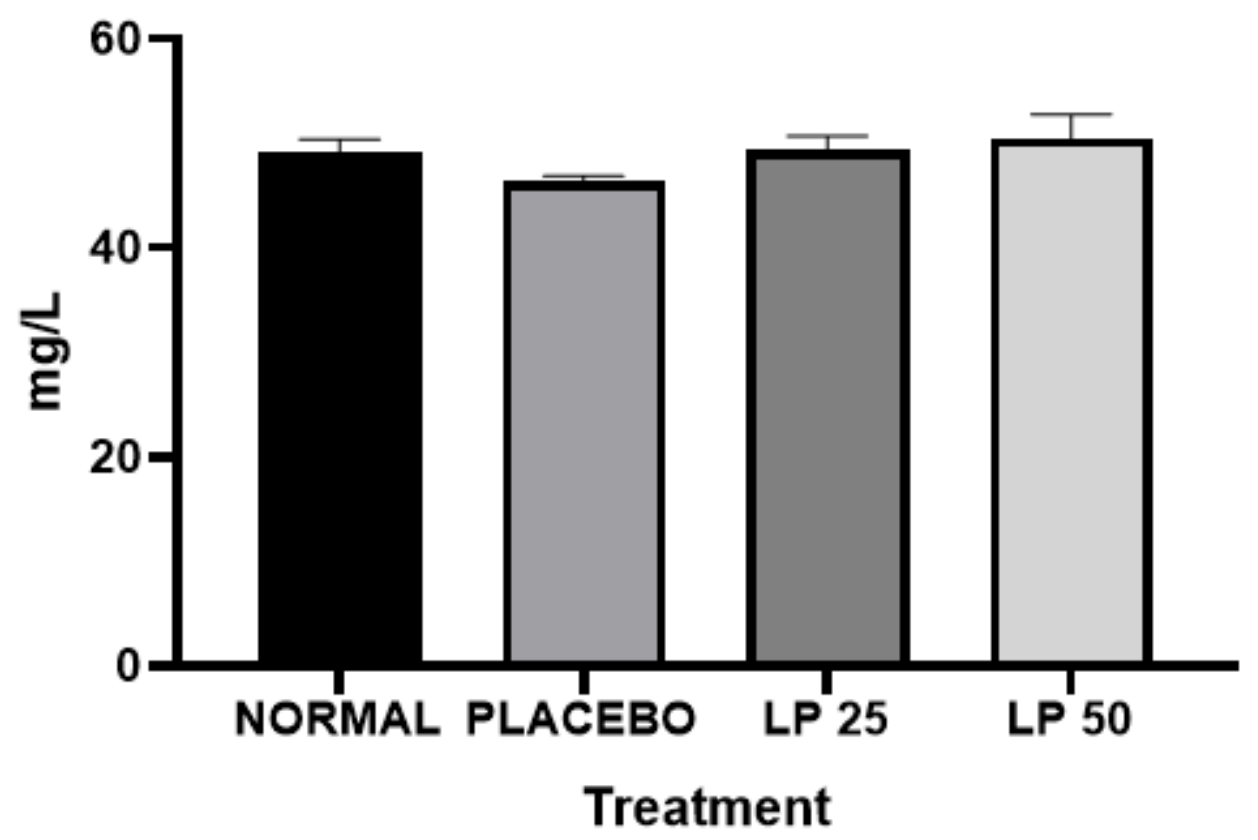

Figure 6

Bone calcium content of PCOS rats. No significant changes in statistical analysis. 


\section{Total Porosity}

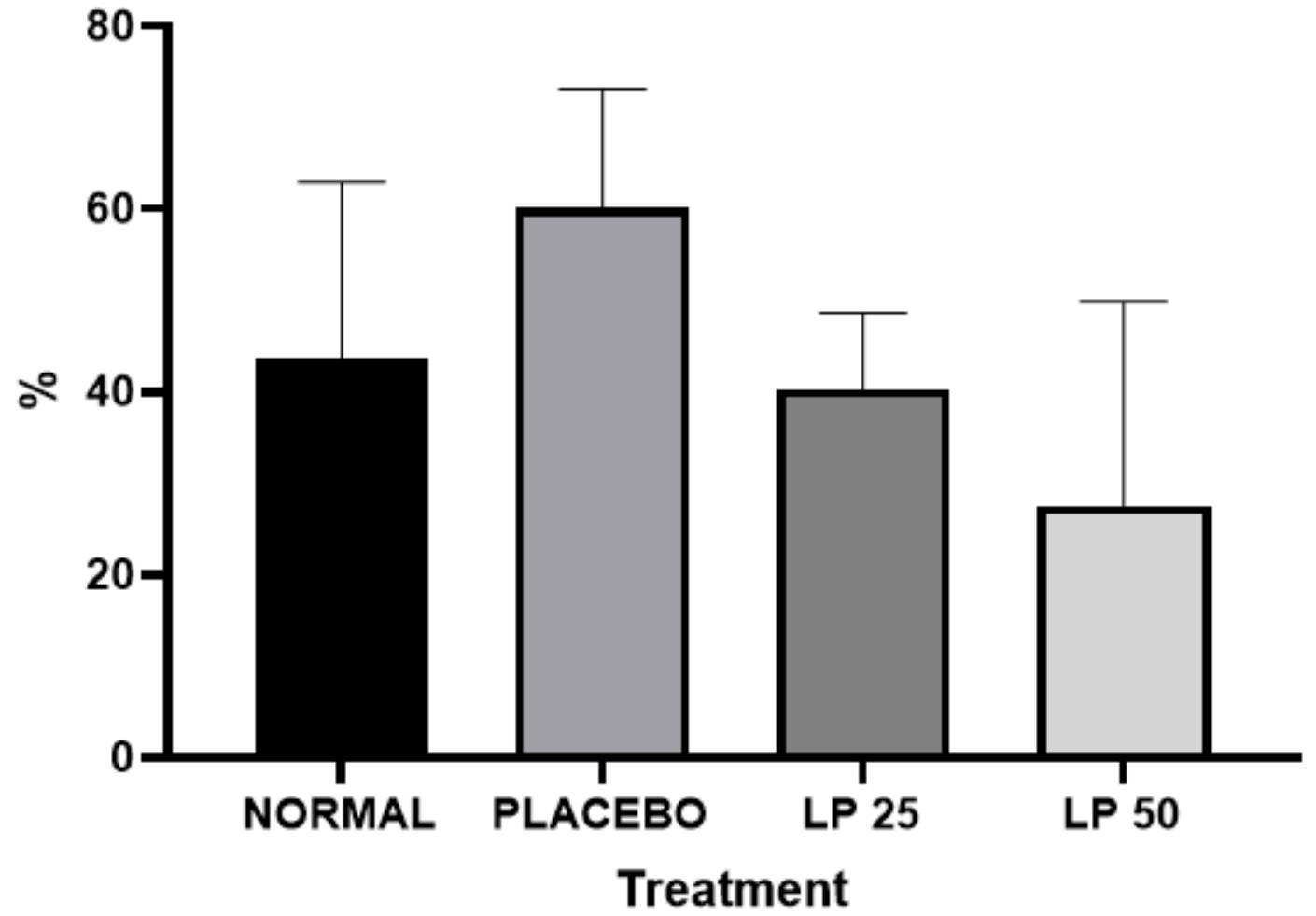

Figure 7

Micro-CT analysis of Total Porosity of PCOS rats. No significant changes in statistical analysis.

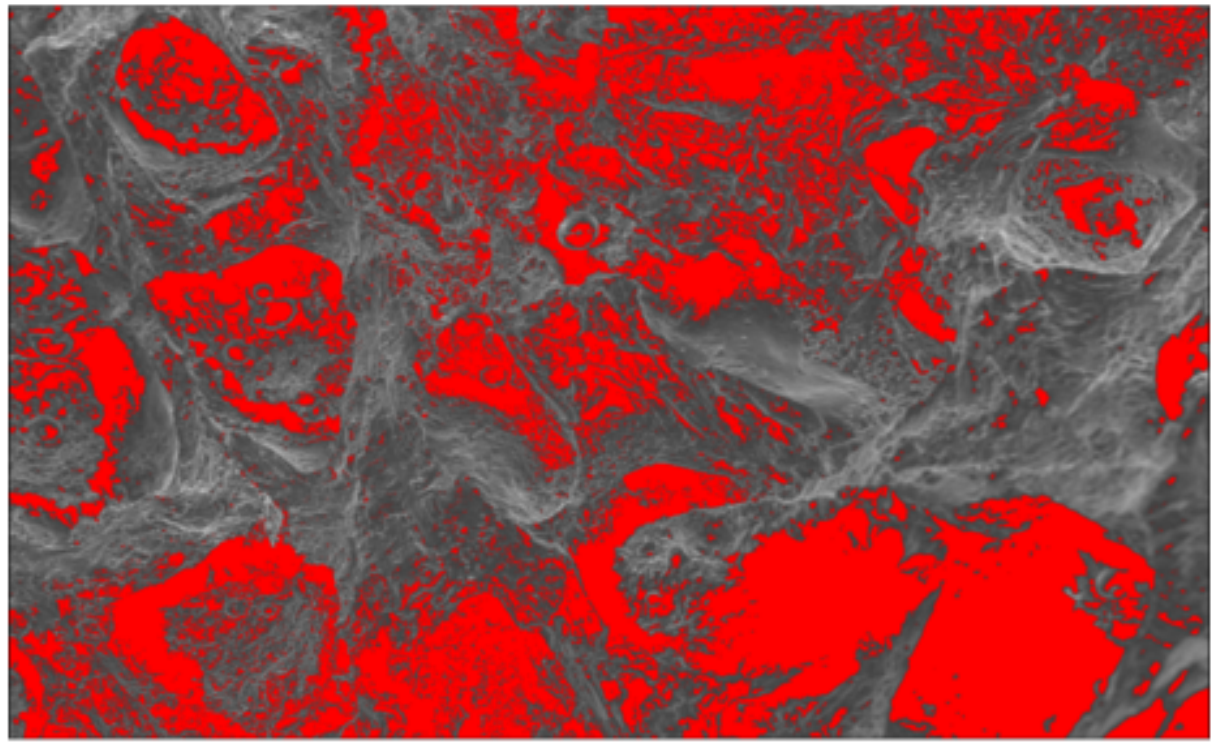

Figure 8 
Image of BSEM of Placebo

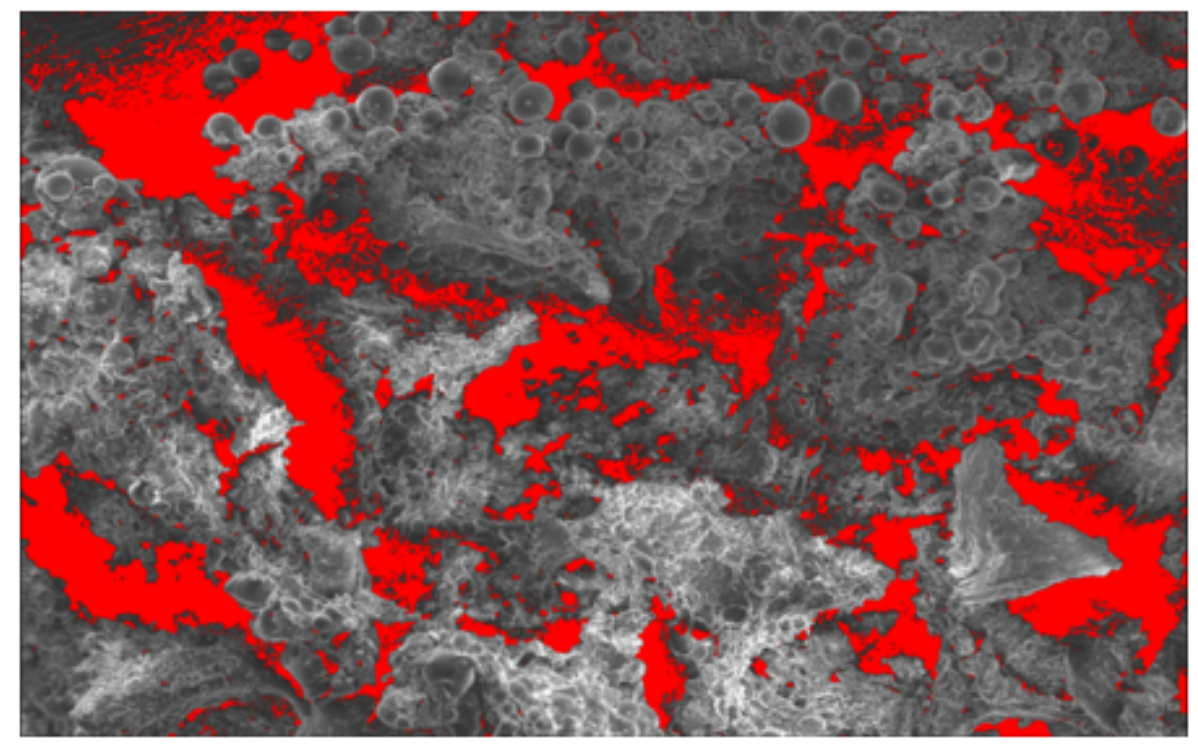

Figure 9

Image of BSEM Control

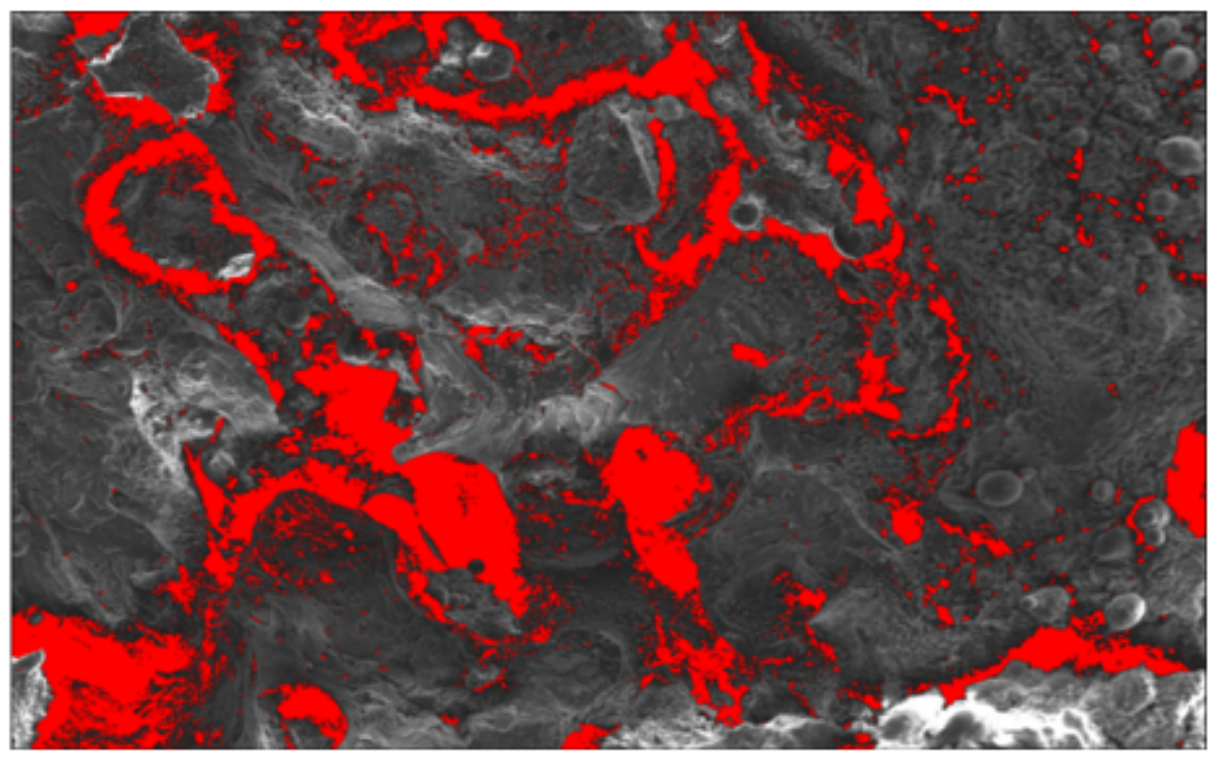

Figure 10

Image of BSEM LP 25 of PCOS rats 


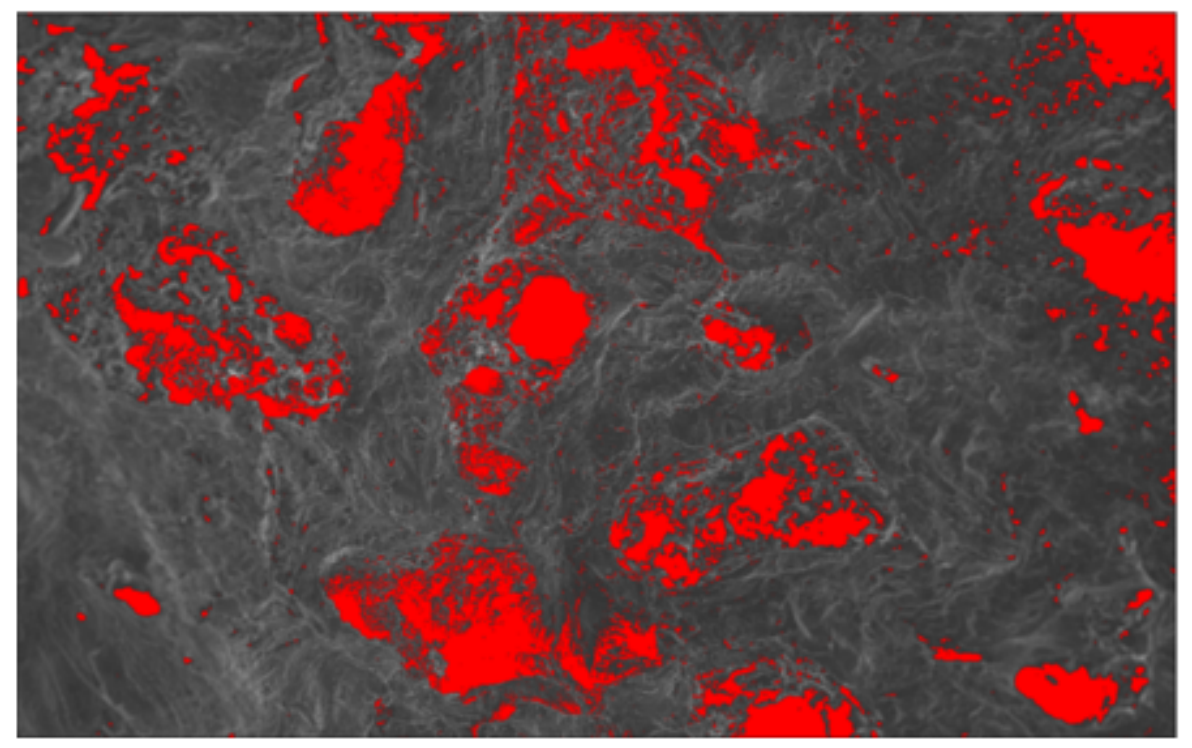

Figure 11

Image of BSEM LP 50 of PCOS rats

\section{C-Reactive Protein}

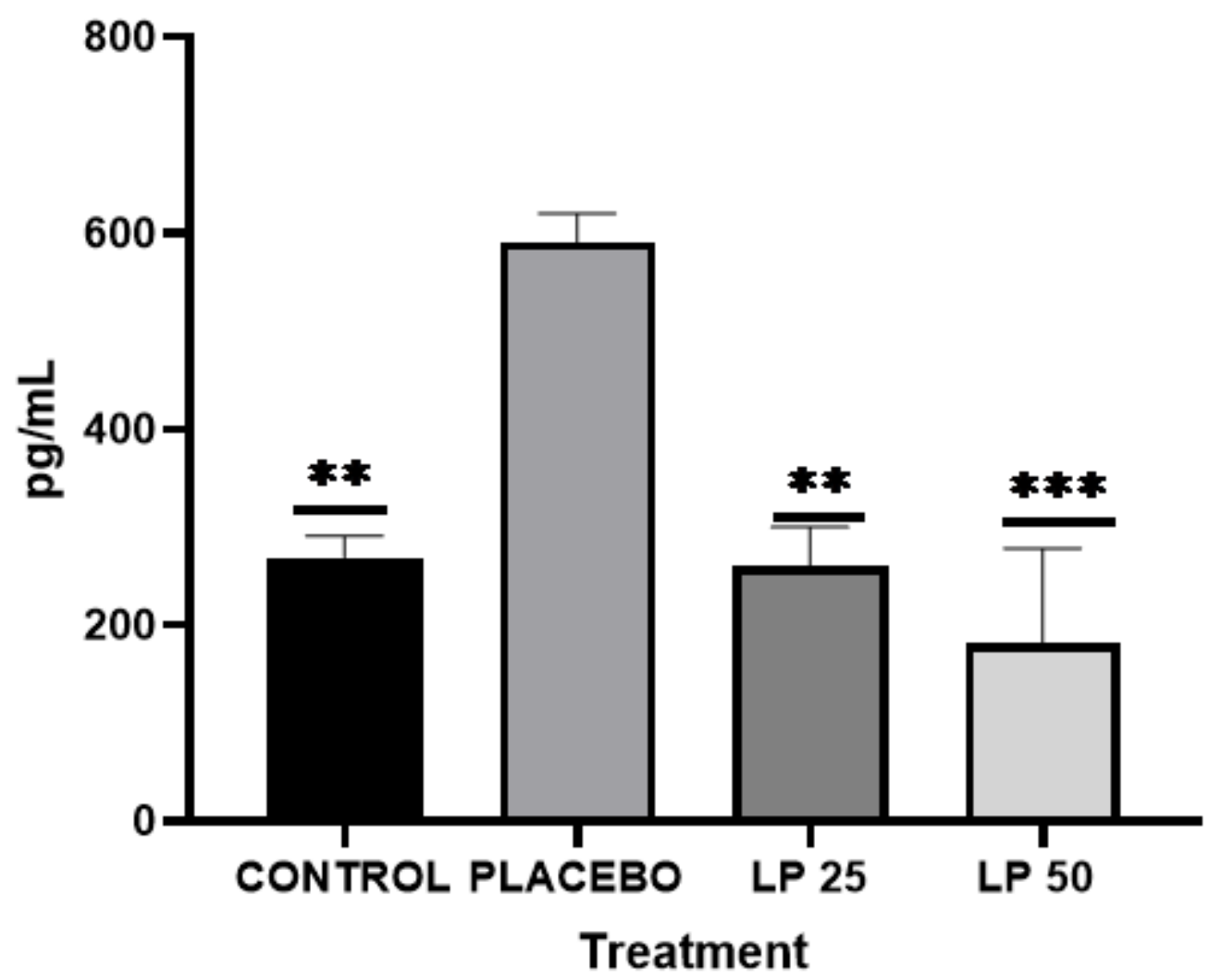

Figure 12

Serum level of C-reactive protein of PCOS rats. * Bars indicant significant changes in statistical analysis. 
TNF-alpha

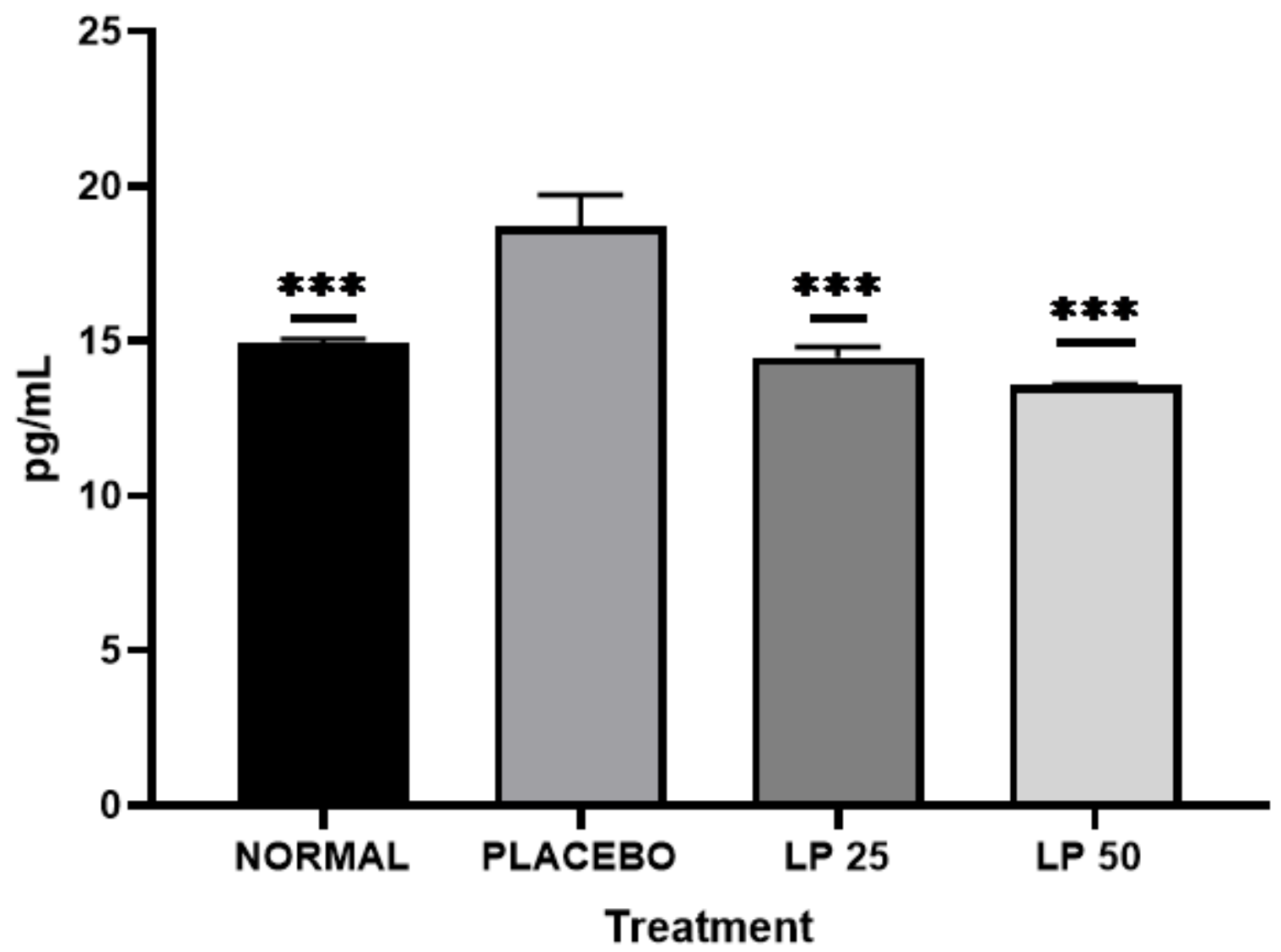

Figure 13

Serum level of TNF-alpha of PCOS rats. * Bars indicate significant changes in statistical analysis. 


\section{Estradiol}

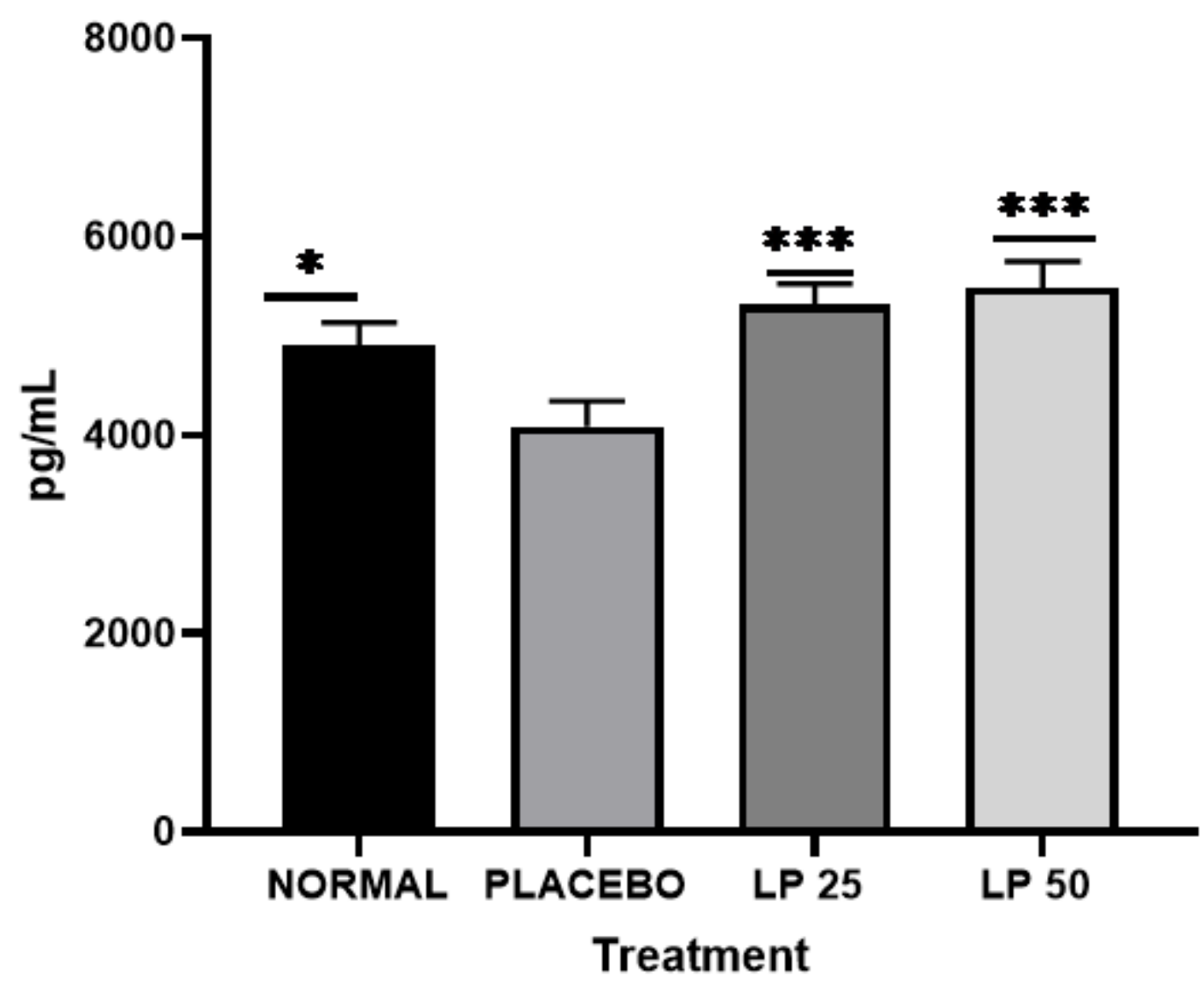

Figure 14

Estradiol level of PCOS rats. * Bars indicate significant changes in statistical analysis 


\section{Testosterone}

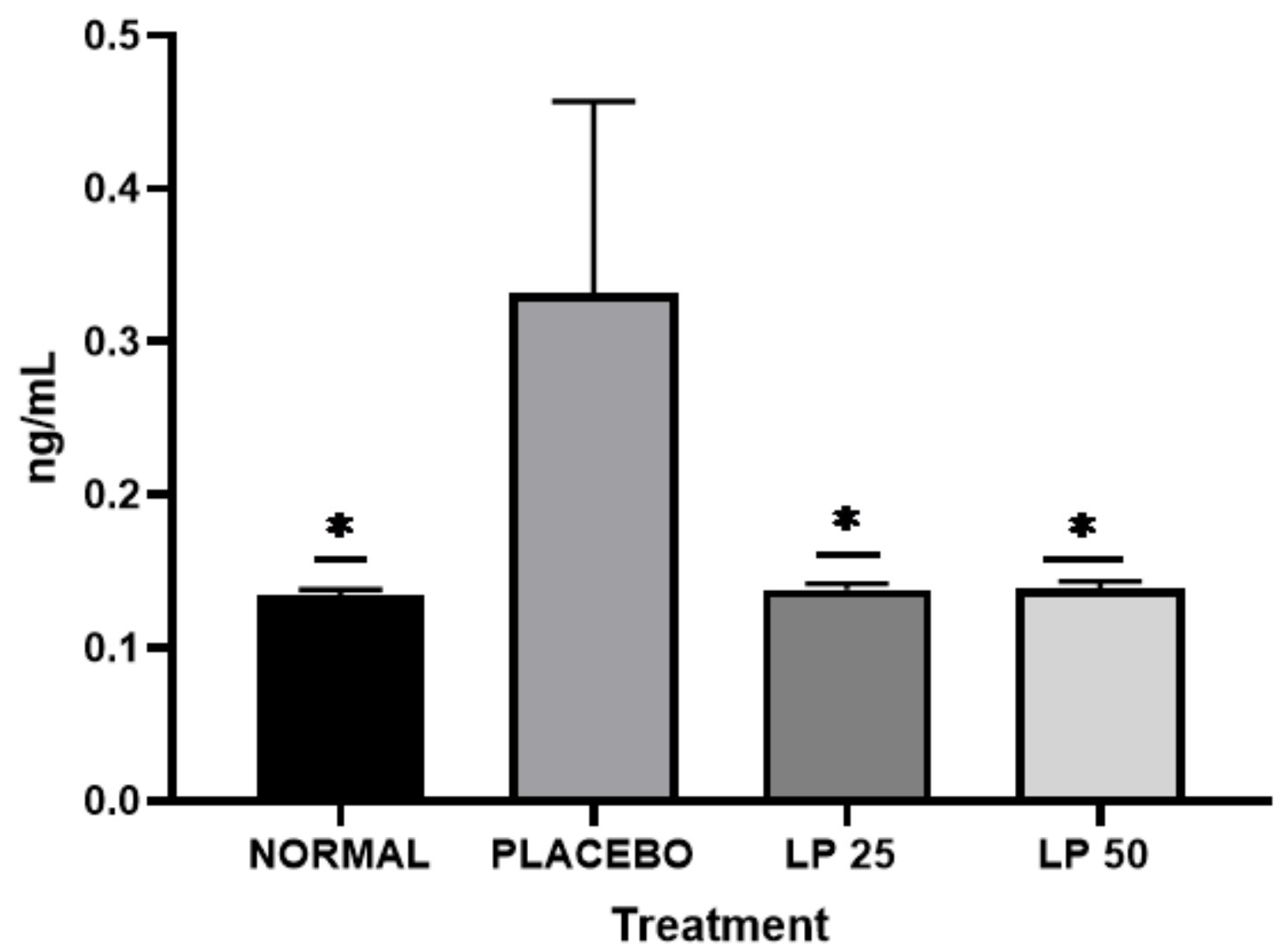

Figure 15

Testosterone level of PCOS rats. * Bars indicate significant changes in statistical analysis. 


\section{Insulin}

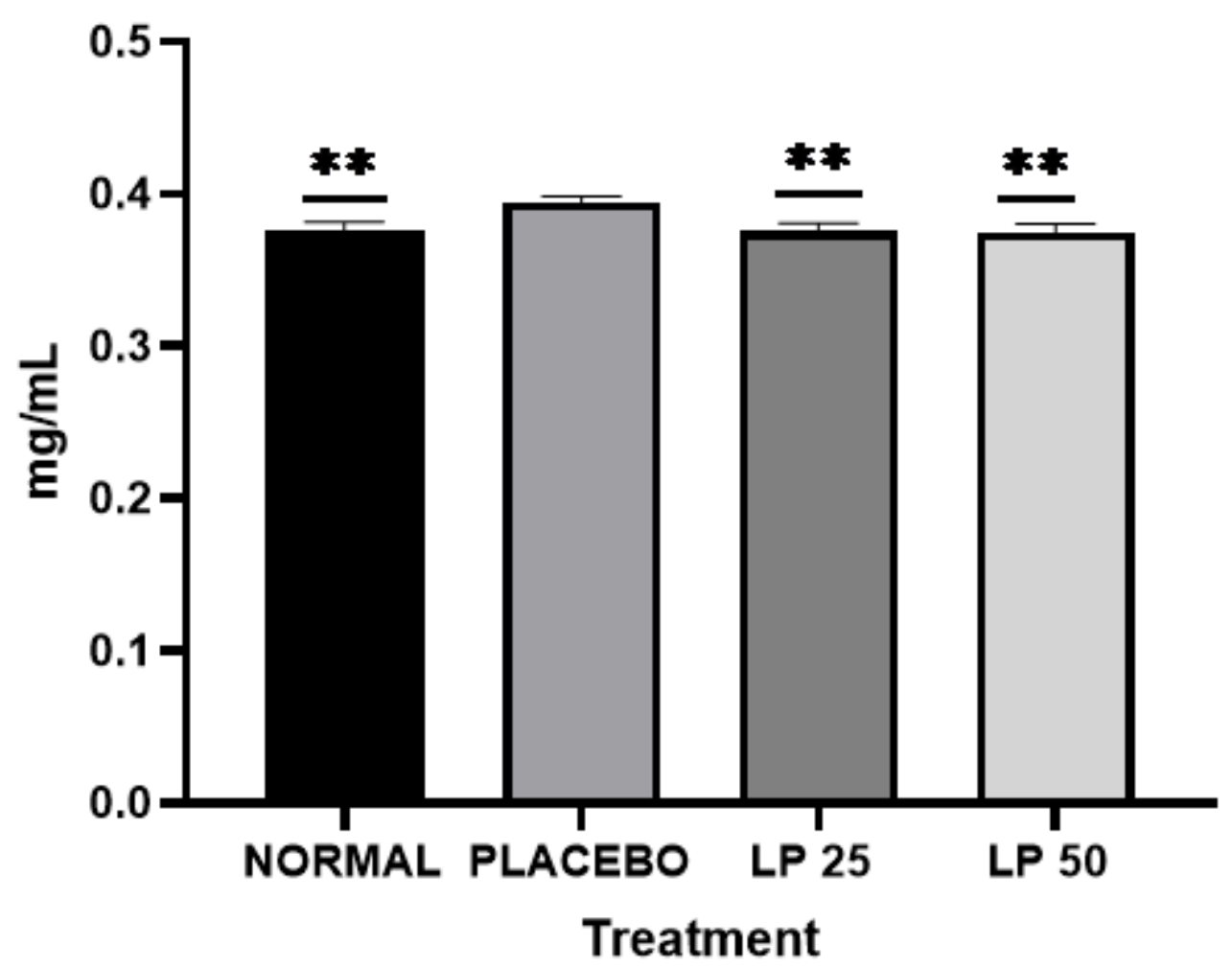

Figure 16

Insulin level of PCOS rats. * Bars indicate significant changes in statistical analysis. 


\section{Skin}

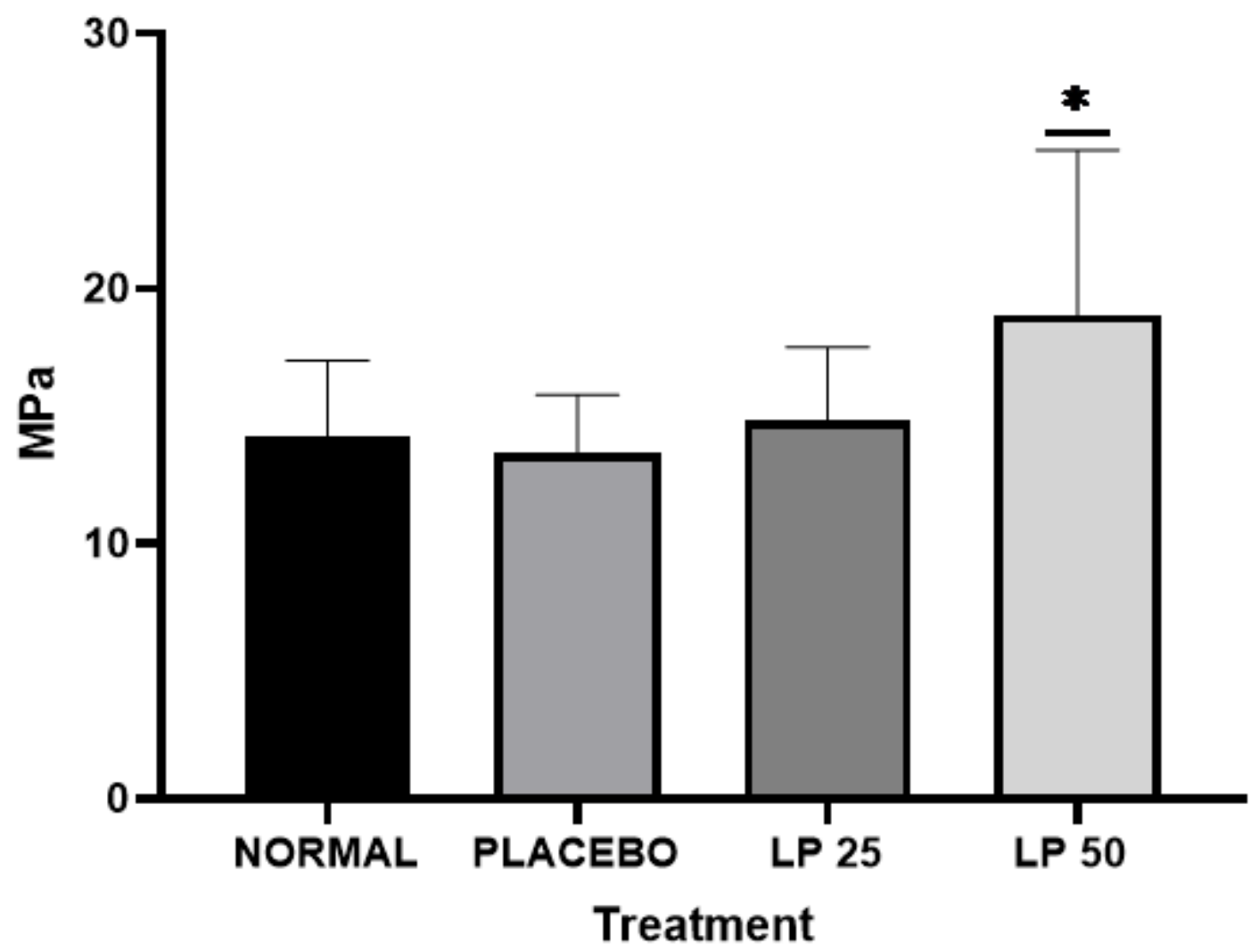

Figure 17

Skin elasticity of PCOS rats. * Bars indicate significant changes in statistical analysis. 


\section{Vagina}

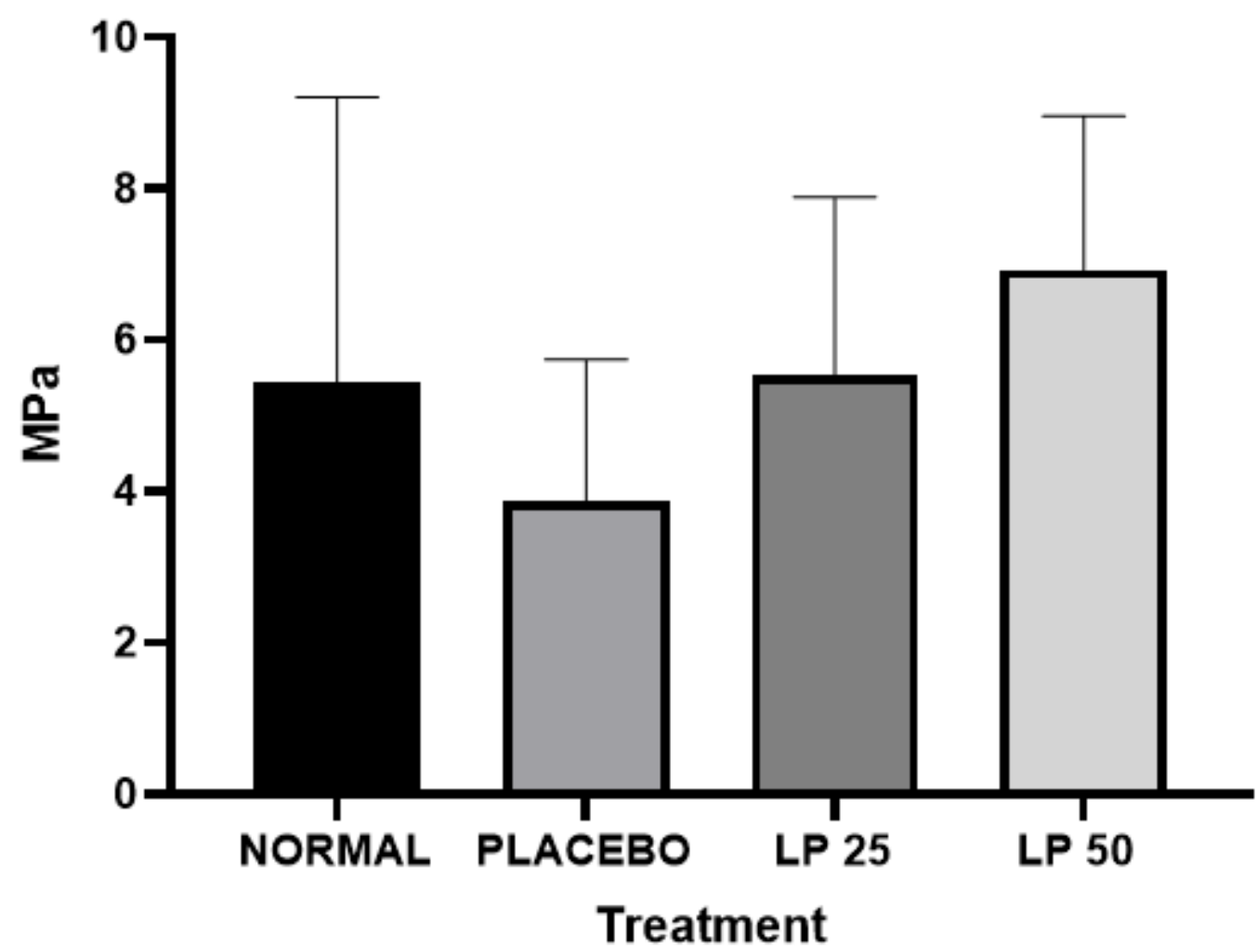

Figure 18

Vagina elasticity of PCOS rats. * Bars indicate significant changes in statistical analysis.

\section{Supplementary Files}

This is a list of supplementary files associated with this preprint. Click to download.

- graphicalabstract.docx 